\title{
Nocturia: Impact on quality of life in an Egyptian adult population
}

\author{
Salma M. S. El Said", Tomader Abd El Rahman, Ahmed K. Mortagy, Marian Wagieh Mansour
}

Geriatrics and Gerontology Department, Faculty of Medicine, Ain Shams University, Cairo, Egypt;

\#Corresponding Author: salmasaied777@gmail.com

Received 20 July 2013; revised 20 August 2013; accepted 27 August 2013

Copyright (C) 2013 Salma M. S. El Said et al. This is an open access article distributed under the Creative Commons Attribution License, which permits unrestricted use, distribution, and reproduction in any medium, provided the original work is properly cited.

\section{ABSTRACT}

OBJECTIVE: To estimate the effects of nocturia on quality of life (QoL) and to assess the associated effects of sleep problems. Background: Nocturnal urination (nocturia) is such a commonplace occurrence in the lives of many older adults that it is frequently overlooked as a potential cause of sleep disturbance. Methods: The current study was carried out to assess the prevalence of nocturia in elderly males and its impact on sleep quality and QoL. The study enrolled 200 elderly males aged 60 years old and above. All participants were recruited from geriatric clubs in Cairo. All participants in the study were subjected to: comprehensive geriatric assessment, American Urological Association (AUA) score was used to measure the severity of nocturia, assessment of sleep quality using Pittsburgh Sleep Quality Index (PSQI) and assessment of QoL using "SF-12 Short Form Health Survey". Results: The study showed that the prevalence of nocturia in elderly males aged $\geq 60$ years old was $68 \%$ with significant association between nocturia and diabetes mellitus, heart failure, stroke, prostatism, recurrent UTI and diuretic use. As regard sleep quality, the current study showed that the prevalence of

\footnotetext{
*Author contributions: Study concept and design: Salma M. S. El Said, Tomader Taha, Mariane Wageih, Analysis and Interpretation of data: Salma M. S. El Said, Tomader Taha, Mariane Wageih, Drafting of the Manuscript: Salma M. S. El Said, Tomader Taha, Mariane Wageih, Critical revision of the manuscript for important intellectual content: Salma M. S. El Said, Tomader Taha, Mariane Wageih, Statistical Analysis: Salma M. S. El Said, Tomader Taha, Mariane Wageih.

Financial Disclosure: All authors have no financial interests related to the material in the manuscript.

Funding support: this study received no financial support

Implications for health policy: the aim of the study was to estimate the effect of nocturia on quality of life (QoL) and to assess the associated effects of sleep problems.
}

poor sleep in the studied subjects is $70.5 \%$ with significant association between nocturia and poor sleep quality. Nocturia significantly affects sleep latency, sleep efficiency and daytime dysfunction, high significantly affecting sleep disturbance. Also diabetes mellitus, ischemic heart disease, heart failure, prostatism, recurrent UTI, osteoarthritis and diuretic use are significantly associated with poor sleep quality. As regard quality of life, the current study showed significant association between nocturia and physical and mental health components of HRQL in the univariate analysis. But after multivariate analysis, nocturia is not an independent risk factor for poor quality of life. Nocturia affects QoL through its effect on sleep quality which is an independent risk factor for poor physical and mental health components of QoL. Conclusion: Nocturia may lead to sleep insufficiency and consequently to a decrease in mental and physical health. Patients who consult a doctor for nocturia should thus be treated adequately. In addition, it is worthwhile for doctors to routinely check if patients who contact them for sleep problems also have nocturia.

Keywords: Nocturia; Sleep Complaints; Quality of Life; Urinary Tract Symptoms

\section{INTRODUCTION}

Nocturia is defined as the complaint that the individual has woken at night one or more time to void [1]. The standard definition for nocturia, by the international continence society, is waking at night to void, applying to any number of voids at any time during night's sleep; each void is preceded and followed by sleep and the person is awake before voiding. Iatrogenic factors such as the use of diu- 
retics for hypertension may also contribute to nocturia. Hence, nocturia is increasingly recognized as a urinary disorder in its own, rather than just a symptom of an underlying disease [2]. Nocturia is an important cause of sleep disruption in men $>50$ years old leading to deterioration of quality of life. Three major conditions inducing nocturia are polyuria (e.g., due to excessive fluid intake or diabetes), nocturnal polyuria (e.g., due to rightsided congestive heart failure or hypoalbuminemia), and reduced bladder capacity (e.g., due to cancer or fibrosis). Reduced bladder capacity, however, is also frequently the result of detrusor over activity or bladder outlet obstruction (BOO) in men with lower urinary tract symptoms suggestive of benign prostatic hyperplasia [3]. Increased severity of nocturia leads to increased sleep disturbance such as frequent awakening and poor sleep [4]. Overlapping causes of frequent urination at night in the aged population have been described, including loss of bladder capacity, decreased glomerular filtration rate, and nocturnal polyuria from decreased arginine vasopressin, incipient diabetes, sleep-disordered breathing, congestive heart failure and/or diuretic use [5]. Lower urinary tract symptoms (LUTS) and, more specifically, lower urinary tract symptoms suggestive of benign prostatic hyperplasia (LUTS/BPH) are a common condition in older men [6].

LUTS/BPH can be divided into either storage or voiding symptoms. According to the International Continence Society (ICS), voiding symptoms, in the past referred to as "obstructive" symptoms, are experienced during the voiding phase of the micturition cycle and include slow stream, intermittent stream, hesitancy, straining and terminal dribble. Storage symptoms, previously referred to as "irritative/filling" symptoms, occur during the storage phase of the micturition cycle and include increased daytime frequency, nocturia, urgency and urinary incontinence [7].

\section{METHODS}

The study is a cross sectional study conducted to assess the prevalence of nocturia and its effect on sleep quality and quality of life in elderly. The study was carried out in 4 geriatric clubs in Cairo (El-Shams Club, Mabaret Talaat $\mathrm{H}$ arb Club, AL Tayaran Club and Sayedat Misr Institution). They were randomly selected. The targeted sample was 200 non-institutionalized, elderly participants between the ages of 60 and 84 inclusive.

\subsection{Tools of Assessment}

Data collection was done for all participants including patients' demographics and medical history.

Every subject undergone: Comprehensive geriatric assessment, assessment of cognitive function using mini- mental state examination (MMSE) [8]. Assessment of mood using geriatric depression scale GDS 15 [9]. Assessment of function using activity of daily living (ADL) [10] and instrumental activity of daily living (IADL). [11]. Assessment of health-related quality of life by the short form 12 health survey (SF12) [12]. Assessment of sleep quality by Pittsburgh sleep quality index [13]. Assessment of severity of prostatic symptoms using American Urological Association symptom index [14]. The SF-12 scale measures eight dimensions: 1) physical functioning; 2) social functioning; 3) bodily pain; 4) activities due to physical problems-role-physical; 5) activities due to emotional problems-role-emotional, 6) emotional wellbeing-mental health; 7) vitality; and 8) general health perceptions. Pittsburgh Sleep Quality Index measures generate seven "component" scores: subjective sleep quality, sleep latency, sleep duration, habitual sleep efficiency, sleep disturbances, use of sleeping medication, and daytime dysfunction. The sum of scores for these seven components yields one global score.

The study was approved by the University and Hospital Ethics Committees.

\subsection{Statistical Analysis}

Data was analyzed using the statistical program SPSS for window, Release 16. All values are reported as mean \pm SD. Chi-square and Fisher's exact tests were used for categorical variables. Multiple logistic regression analysis was performed to determine the independent risk factors for developing hypomagnesaemia during the ICU stay. Relative risk is given with the $95 \%$ confidence interval (CI). Pearson's correlation coefficient and linear regression were used to evaluate the relationship between $\mathrm{Mg}$ and other variables. A $p$ value of $<0.05$ was considered as statistically significant.

\section{RESULTS}

The current study involves 200 elderly males aged 60 years and above. 70 subjects aged 60 - 64 years old, 60 subjects aged 65 - 69 years old, 45 subjects aged $70-74$ years old, 22 aged 75 - 79 years old and 3 subjects aged 80 years old and above. $86.5 \%$ were highly educated. As regard marital status $72.5 \%$ were married, $18.5 \%$ widow, $6 \%$ divorced and $3 \%$ singles.

The studied subjects were $32.5 \%$ diabetic, $55.5 \%$ hypertensive, 5\% heart failure, 6\% COPD, 5\% Asthmatic, $1 \%$ had previous history of stroke, $29 \%$ have prostatic symptoms, $10.5 \%$ have history of recurrent UTI, $1 \%$ have history of prostatectomy, 3\% have history of kidney disease, $1 \%$ incontinent, $39.5 \%$ have constipation, $1.5 \%$ have history of cancer, $3 \%$ have hepatic disease, $41.5 \%$ have visual impairment, $10 \%$ have hearing impairment, $3.5 \%$ depressed, $44.5 \%$ have osteoarthritis and 14\% us- 
ing diuretics (Table 1).

The prevalence of nocturia in the studied subjects was $68 \% ; 22.5 \%$ awake once at night to void, $19 \%$ awake twice to void, $14 \%$ awake three times to void, $7.5 \%$ awake four times to void and $5 \%$ awake five times to void (Table 2).

The prevalence of poor sleep quality was $70.5 \%$ in the studied group (Table 3). Nocturia has significant relation with sleep latency, sleep efficiency and daytime dysfunction, highly significant relation with sleep disturbance and non significant relation with subjective sleep quality, sleep duration and use of sleep medication. There is significant relation between sleep quality and physical and mental components of quality of life (Table 4).

Table 1. Prevalence of medical conditions.

\begin{tabular}{cccc}
\hline Disease & & N. & Percent (\%) \\
\hline Diabetic & Yes & 65 & 32.5 \\
Hypertension & Yes & 111 & 55.5 \\
Ischemic heart & Yes & 47 & 23.5 \\
Heart failure & Yes & 10 & 5.0 \\
COPD & Yes & 12 & 6.0 \\
Bronchial asthma & Yes & 10 & 5.0 \\
Stroke & Yes & 2 & 1.0 \\
Prostatism & Yes & 58 & 29.0 \\
Recurrent UTI & Yes & 21 & 10.5 \\
Prostatectomy & Yes & 2 & 1.0 \\
Kidney disease & Yes & 6 & 3.0 \\
Incontinence & Yes & 2 & 1.0 \\
Constipation & Yes & 79 & 39.5 \\
Cancer & Yes & 3 & 1.5 \\
Liver disease & Yes & 6 & 3.0 \\
Visual impairment & Yes & 83 & 41.5 \\
\hline & & &
\end{tabular}

Table 2. Prevalence of Nocturia among studied subjects.

\begin{tabular}{cccc}
\hline \multirow{4}{*}{ Nocturia } & & N. & Percent (\%) \\
\hline \multirow{7}{*}{ Grades } & No & 64 & 32.0 \\
& Yes & 136 & 68.0 \\
& 0.00 & 64 & 32.0 \\
& 1.00 & 45 & 22.5 \\
& 2.00 & 38 & 19.0 \\
& 3.00 & 28 & 14.0 \\
& 4.00 & 15 & 7.5 \\
& 5.00 & 10 & 5.0 \\
\hline
\end{tabular}

Nocturia has significant relation with poor sleep quality. Nocturia has significant relation with AUA score and MMSE, and no significant relation with GDS and IADL (Table 5).

Table 3. Prevalence of poor sleep in studied subjects.

\begin{tabular}{ccc}
\hline Sleep quality & Frequency & Percent \\
\hline Poor sleep quality & 141 & 70.5 \\
Good sleep quality & 59 & 29.5 \\
Total & 200 & 100.0 \\
\hline
\end{tabular}

Table 4. The relation between nocturia and sleep quality components.

\begin{tabular}{|c|c|c|c|c|c|}
\hline \multicolumn{2}{|c|}{$\begin{array}{l}\text { Sleep quality } \\
\text { components }\end{array}$} & \multicolumn{2}{|c|}{ Nocturia } & \multirow[t]{2}{*}{$\mathrm{X}^{2}$} & \multirow[t]{2}{*}{$\mathrm{P}$} \\
\hline & & No $(n=64)$ & Yes $(n=136)$ & & \\
\hline \multirow{4}{*}{$\begin{array}{l}\text { Subjective } \\
\text { sleep quality }\end{array}$} & 0 & $17(26.6 \%)$ & $21(15.4 \%)$ & \multirow{4}{*}{4.95} & \multirow{4}{*}{0.17} \\
\hline & 1 & $33(51.6 \%)$ & $73(53.7 \%)$ & & \\
\hline & 2 & $10(15.6 \%)$ & $35(25.7 \%)$ & & \\
\hline & 3 & $4(6.3 \%)$ & $7(5.1 \%)$ & & \\
\hline \multirow{4}{*}{$\begin{array}{l}\text { Sleep } \\
\text { latency }\end{array}$} & 0 & $15(23.4 \%)$ & $13(9.6 \%)$ & \multirow{4}{*}{7.713} & \multirow{4}{*}{0.042} \\
\hline & 1 & $27(42.2 \%)$ & $57(41.9 \%)$ & & \\
\hline & 2 & $15(23.4 \%)$ & $48(35.3 \%)$ & & \\
\hline & 3 & $7(10.9 \%)$ & $18(13.2 \%)$ & & \\
\hline \multirow{4}{*}{$\begin{array}{c}\text { Sleep } \\
\text { duration }\end{array}$} & 0 & $9(14.1 \%)$ & $17(12.5 \%)$ & \multirow{4}{*}{1.55} & \multirow{4}{*}{0.678} \\
\hline & 1 & $21(32.8 \%)$ & $55(40.4 \%)$ & & \\
\hline & 2 & $26(40.6 \%)$ & $45(33.1 \%)$ & & \\
\hline & 3 & $8(12.5 \%)$ & $19(14 \%)$ & & \\
\hline \multirow{4}{*}{$\begin{array}{c}\text { Sleep } \\
\text { efficiency }\end{array}$} & 0 & $29(45.3 \%)$ & $37(27.2 \%)$ & \multirow{4}{*}{6.58} & \multirow{4}{*}{0.014} \\
\hline & 1 & $23(35.9 \%)$ & $58(42.6 \%)$ & & \\
\hline & 2 & $10(15.6 \%)$ & $33(24.3 \%)$ & & \\
\hline & 3 & $2(3.1 \%)$ & $8(5.9 \%)$ & & \\
\hline \multirow{4}{*}{$\begin{array}{c}\text { Sleep } \\
\text { disturbance }\end{array}$} & 0 & $22(34.4 \%)$ & $0(0.0 \%)$ & \multirow{4}{*}{63.08} & \multirow{4}{*}{0.000} \\
\hline & 1 & $38(59.4 \%)$ & $89(65.4 \%)$ & & \\
\hline & 2 & $4(6.3 \%)$ & $46(33.8 \%)$ & & \\
\hline & 3 & $0(0.0 \%)$ & $10(7 \%)$ & & \\
\hline \multirow{4}{*}{$\begin{array}{l}\text { Use of sleep } \\
\text { medications }\end{array}$} & 0 & $56(87.5 \%)$ & $122(89.7 \%)$ & \multirow{4}{*}{2.50} & \multirow{4}{*}{0.523} \\
\hline & 1 & $3(4.7 \%)$ & $8(5.9 \%)$ & & \\
\hline & 2 & $4(6.7 \%)$ & $6(4.4 \%)$ & & \\
\hline & 3 & $1(1.6 \%)$ & $0(0.0 \%)$ & & \\
\hline \multirow{4}{*}{$\begin{array}{l}\text { Daytime } \\
\text { dysfunction }\end{array}$} & 0 & $39(60.9 \%)$ & $57(41.9 \%)$ & \multirow{4}{*}{6.285} & \multirow{4}{*}{0.015} \\
\hline & 1 & $14(21.9 \%)$ & $39(28.7 \%)$ & & \\
\hline & 2 & $9(14.1 \%)$ & $31(22.8 \%)$ & & \\
\hline & 3 & $2(3.1 \%)$ & $9(6.6 \%)$ & & \\
\hline
\end{tabular}


Table 5. The relation between Nocturia and other assessment tools.

\begin{tabular}{ccccccc}
\hline & Nocturia & $\mathbf{N}$ & Mean & \pm SD & t & P value \\
\hline \multirow{2}{*}{ AUA } & No & 64 & 3.0 & 2.7 & -7.451 & 0.000 \\
& Yes & 136 & 9.6 & 6.8 & & \\
\multirow{2}{*}{ MMSE } & No & 64 & 29.8 & 0.4 & & \\
& Yes & 136 & 29.4 & 1.0 & 3.285 & 0.001 \\
& No & 64 & 2.3 & 1.9 & & \\
GDS & Yes & 136 & 2.7 & 1.8 & -1.401 & 0.163 \\
& No & 64 & 2.0 & $0.00000^{(\mathrm{a})}$ & & \\
ADL & Yes & 136 & 2.0 & $0.00000^{(\mathrm{a})}$ & - & - \\
& No & 64 & 1.9 & 0.3 & & \\
IADL & Yes & 136 & 1.9 & 0.3 & -0.490 & 0.625 \\
& & &
\end{tabular}

(a) $t$ cannot be computed because the standard deviations of both groups are 0 .

\section{DISCUSSION}

The current study was carried out to assess the prevalence of nocturia and its impact on sleep quality and quality of life.

The study enrolled 200 elderly males. In current study were nocturia was defined as voiding once or more at night, the prevalence of nocturia was $68 \%$ in the studied subjects. The prevalence was $62.9 \%$ among subjects aged 60 - 64 years, $66.7 \%$ among subjects aged $65-69$, $71.1 \%$ among subjects aged $70-74$ years, $81.8 \%$ among subjects aged 75 - 79 years, $66.7 \%$ among subjects aged 80 years and over.

The estimated prevalence of nocturia has varied, largely due to differences in symptom assessment, study population, data collection, and definitions used (Hunskaar, 2005) [15]. In the current study the prevalence of nocturia increase with age but this increase was not significant. This disagreed with other studies, for example; Yoshimura et al. (2004) [16] that showed significant increase in nocturia with age when elderly compared with young age. Tikkinen et al. (2010) [17] that concluded increase in nocturia with age in both gender and Markland et al. (2011) [18] study of 5297 men in USA (20 years old or older) which showed that the nocturia significantly increase with age from $8.2 \%$ in men $20-34$ years old up to $55.8 \%$ in men 75 years old or older, with significant increase with 10 years increase in age. This increasing prevalence is largely due to age-related physiological changes (Boongird et al., 2010) [19] and increase in percentage of urine produced at night with age as younger people producing less urine at night than older people (Van Kerrebroeck et al., 2002) [20]. This non significant increase in nocturia prevalence with age in the current study despite significant increase with age in other studies could be attributed to that all our studied subjects were elderly aged 60 and above years old and only 3 subjects over 80 years old. There was no younger age group to compare and detect the significance of increase in age. Using AUA symptom score to assess the severity of prostatic symptoms revealed that patient with nocturia scores higher in AUA score and the increase in severity of LUTS is associated with increase in severity in nocturia ( $\mathrm{P}$ value 0.000 ). This agreed with a study enrolled patients aged 60 years or older with LUTS/BPH, patients with nocturia had a markedly higher I-PSS score $(19.9 \pm 4.6)$ as compared to those without nocturia (15.4 $\pm 3.0)(\mathrm{P}<0.001)$ (Hernández et al., 2010) [21]. In the current study, there is significant correlation between recurrent UTI and nocturia. This agreed with Weiss \& Blaivas (2002) [22] as infection cause bladder irritations which result in storage problem and lead to nocturia. As regard sleep quality, using Pittsburgh Sleep Quality Index, current study revealed significant affection of sleep quality associated with nocturia, significant correlation between nocturia and 4 subscales of PSQI (sleep latency, sleep efficiency, sleep disturbance and day time dysfunction) and significant affection of total score ( $\mathrm{P}$ value 0.003 ) as the mean of PSQI total score in non nocturic is $6 \pm 4 \mathrm{SD}$ and the mean of PSQI total score in nocturic is $7.7 \pm 3.7$ SD. That was agreed with several studies using different standard psychometric instruments for measuring sleep quality which also reported that nocturia is associated with disrupted sleep. Cai et al., (2006) [23] reported that scores suggesting poor quality of sleep on most subscales of the Pittsburgh Sleep Quality Index (PSQI) correlated with severity of nocturia; similar findings of sleep disturbance were noted on the Nordic Sleep Questionnaire insomnia subscale (Drake et al., 2005) [24] and Medical Outcomes Study Sleep Scale (Lau et al., 2006) [25]. As regard HRQL, our current study, using the quality of life questionnaire SF-12, revealed that nocturia affect 7 domains in SF-12 out of 8. There was highly significant association between nocturia and energy and social functioning, significant associations between nocturia and limitation due to physical health, limitation due to emotional problem, emotional well-being, pain and general health and though affecting both physical and mental component summary of QoL. This is through the effect of nocturia on sleep which is an independent risk factor affecting HRQL. This was agreed with a study in Boston, using SF-12 HRQL questionnaire, that showed that nocturia is associated with low physical and mental health component scores (Kupelian et al., 2012) [26].

\section{CONCLUSION AND RECOMMENDATIONS}

In conclusion, respondents who felt bothered by at least one void/night have more sleep problems and a 
poorer QoL than those with nocturia but no bother, or no nocturia. The effect of nocturia on QoL is mediated by sleep.

As nocturia might cause sleep insufficiency and a resulting decrease in mental and Physical health, patients who consult a doctor for nocturia should be treated adequately. For the same reason, it is worthwhile for doctors to routinely check if patients who contact them for sleeping disorders also have nocturia.

\section{REFERENCES}

[1] Peters, T.J., Donovan, J.L., Kay, H.E., et al. (1997) The International Continence Society "Benign Prostatic Hyperplasia" study: The bothersomeness of urinary symptoms [see comments]. Journal of Urology, 157, 885-889. http://dx.doi.org/10.1016/S0022-5347(01)65075-4

[2] Van Kerrebroeck, P., Abrams, P., Chaikin, D., et al. (2002) The standardization of terminology in nocturia: Report from the standardization subcommittee of the International Continence Society. BJU International, 90, 11-15. http://dx.doi.org/10.1046/j.1464-410X.90.s3.3.x

[3] Abrams, P. (2005) Nocturia: The major problem in patients with lowers urinary tract symptoms suggestive of benign prostatic obstruction (LUTS/BPO). European Urology Supplements, 3, 8-16.

http://dx.doi.org/10.1016/S1569-9056(05)80002-8

[4] Schulman, C.C., Asplund, R., Desgrandchamps, F., et al. (2005) The impact of nocturia on health status and quality of life in patients with lower urinary tract symptoms suggestive of benign prostatic hyperplasia (LUTS/BPH). European Urology Supplements, 4, 1-8. http://dx.doi.org/10.1016/j.eursup.2004.10.007

[5] Miller, M. (2000) Nocturnal polyuria in older people: Pathophysiology and clinical implications. Journal of the American Geriatrics Society, 48, 1321-1329.

[6] Thorpe, A. and Neal, D. (2003) Benign prostatic hyperplasia. Lancet, 361, 135-167. http://dx.doi.org/10.1016/S0140-6736(03)13073-5

[7] Abrams, P., Cardozo, L., Fall, M., et al. (2002) The standardisation of terminology in lower urinary tract function: Report from the standardisation sub-committee of the International Continence Society. Neurourology and Urodynamics, 21, 167-178.

http://dx.doi.org/10.1002/nau.10052

[8] Folestein, M.F., Folestein, S. and McHugh, P.R. (1975) Mini-mental state. A practical method for grading the cognitive state of patients for the clinicians. Journal of Psychiatric Research, 12, 189-198.

[9] Sheikh, J.A. and Yesavage, J.A. (1986) Recent finding and development of a shorter version. In: Brinn, T.L., Ed., Clinical Gerontology: A Guide to Assessment and Intervention, Hawarth Press, New York, 165-173.

[10] Katz, S., Ford, A., Moskowitz, R., et al. (1963) The index of activities of daily living standardized measure of biological and psychological function. The JAMA Network, 185, 914-919. http://dx.doi.org/10.1001/jama.1963.03060120024016

[11] Lawton, M. and Brody, E. (1969) Assessment of older people: Self-maintaing and instrumental activities of daily living. Gerontologist, 9, 176-186.

http://dx.doi.org/10.1093/geront/9.3_Part_1.179

[12] Ware, J.E., Kosinski, M. and Keller, S.D. (1996) A 12item short-form health survey: Construction of scales and preliminary tests of reliability and validity. Medical Care, 34, 220-233. http://dx.doi.org/10.1097/00005650-199603000-00003

[13] Buysse, D.J., Reynolds, C.F., Monk, T.H., et al. (1989) The Pittsburgh sleep quality index: A new instrument for psychiatric practice and research. Psychiatry Research, 28, 193-213. http://dx.doi.org/10.1016/0165-1781(89)90047-4

[14] Barry, M.J., Fowler Jr., F.J., O’Leary, M.P., et al. (1992) The American Urological Association symptom index for benign prostatic hyperplasia. The Measurement Committee of the American Urological Association. Journal of Urology, 148, 1549-1557.

[15] Hunskaar, S. (2005) Epidemiology of nocturia. BJU International, 96, 4-7. http://dx.doi.org/10.1111/j.1464-410X.2005.05650.x

[16] Yoshimura, K., Terada, N., Matsui, Y., et al. (2004) Prevalence of and risk factors for nocturia: Analysis of a health screening program. International Journal of Urology, 11, 282-287. http://dx.doi.org/10.1111/j.1442-2042.2004.00791.x

[17] Tikkinen, K.A., Johnson 2nd, T.M., Tammela, T.L., et al. (2010) Nocturia frequency, bother, and quality of life: How often is too often? A population-based study in Finland. European Urology, 57, 488-498.

http://dx.doi.org/10.1016/j.eururo.2009.03.080

[18] Markland, A.D., Vaughan, C.P., Johnson, T.M., et al. (2011) Prevalence of nocturia in United States men: Results from the National Health and Nutrition Examination Survey. Journal of Urology, 185, 998-1002. http://dx.doi.org/10.1016/i.juro.2010.10.083

[19] Boongird, S., Shah, N., Nolin, T.D., et al. (2010) Nocturia and aging: Diagnosis and treatment. Advances in Chronic Kidney Disease, 17, e27-e40.

http://dx.doi.org/10.1053/j.ackd.2010.04.004

[20] Van Kerrebroeck, P., Abrams, P., Chaikin, D., et al. (2002) The standardization of terminology in nocturia: Report from the standardization subcommittee of the International Continence Society. BJU International, 90, 11-15. http://dx.doi.org/10.1046/j.1464-410X.90.s3.3.x

[21] Hernández, C., Estivill, E. and Cantalapiedra, A. (2010) Impact of nocturia on sleep quality in patients with lower urinary tract symptoms suggesting benign prostatic hyperplasia (LUTS/BPH). The NocSu study. Actas Urologicas Espanolas, 34, 450-459.

http://dx.doi.org/10.1016/j.acuro.2010.02.008

[22] Weiss, J.P. and Blaivas, J.G. (2002) Nocturnal polyuria versus overactive bladder in nocturia. Urology, 60, 28-32. http://dx.doi.org/10.1016/S0090-4295(02)01789-2

[23] Cai, T., Gardener, N., Abraham, L., et al. (2006) Impact of surgical treatment on nocturia in men with benign 
prostatic obstruction. BJU International, 98, 799-805. http://dx.doi.org/10.1111/j.1464-410X.2006.06380.x

[24] Drake, N.L., Flynn, M.K., Romero, A.A., et al. (2005) Nocturnal polyuria in women with overactive bladder symptoms and nocturia. American Journal of Obstetrics \& Gynecology, 192, 1682-1686.

http://dx.doi.org/10.1016/j.ajog.2004.11.033

[25] Lau, D.T., Morlock, R.J. and Hill, C.D. (2006) Psycho- metric evaluation of the medical outcomes study-sleep scale in persons with overactive bladder. Clinical Therapeutics, 28, 2119-2132.

http://dx.doi.org/10.1016/j.clinthera.2006.12.008

[26] Kupelian, V., Wei, J.T., O’Leary, M.P., et al. (2012) Nocturia and quality of life: Results from the Boston area community health survey. European Urology, 61, 78-84. http://dx.doi.org/10.1016/j.eururo.2011.05.065 